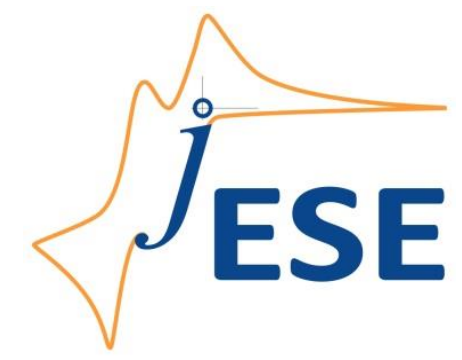

Open Access : : ISSN 1847-9286

www.jESE-online.org

Original scientific paper

\title{
Inhibition of carbon steel corrosion by 11-aminoundecanoic acid
}

\author{
Saad Ghareba ${ }^{\bowtie}$, Simon Kwan*, Sasha Omanovic* \\ Department of Chemical and Petroleum Engineering, Al-Mergib University, Alkhums Libya \\ *Department of Chemical Engineering, McGill University, Montreal, Quebec, Canada \\ ${ }^{\otimes}$ Corresponding Author: smghareba@elmergib.edu.ly
}

Received: October 18, 2015; Revised: November 24, 2015; Accepted: November 27, 2015

\begin{abstract}
The current study reports results on the investigation of the possibility of using 11aminoundecanoic acid (AA) as an inhibitor of general corrosion of carbon steel (CS) in $\mathrm{HCl}$ under a range of experimental conditions: inhibitor concentration, exposure time, electrolyte temperature and $\mathrm{pH}$ and CS surface roughness. It was found that AA acts as a mixed-type inhibitor, yielding maximum inhibition efficiency of $97 \%$. The adsorption of $A A$ onto the CS surface was described by the Langmuir adsorption isotherm. The corresponding apparent Gibbs free energy of AA adsorption on CS at $295 \mathrm{~K}$ was calculated to be $-30.2 \mathrm{~kJ} \mathrm{~mol}^{-1}$. The adsorption process was found to be driven by a positive change in entropy of the system. PM-IRRAS measurements revealed that the adsorbed AA layer is amorphous, which can be attributed to the repulsion between the neighboring positively charged amine groups and a high heterogeneity of the CS surface. It was also found that the AA provides very good corrosion protection of CS of various surface roughness, and over a prolonged time.
\end{abstract}

\section{Keywords}

Corrosion inhibition; Self-assembled monolayers; Adsorption; Acidic medium

\section{Introduction}

Acidization of a petroleum oil well is one of the important stimulation techniques for enhancing oil production [1]. In general, acid solutions are used in pickling processes, industrial acid cleaning, oil and gas well acidizing and for removal of rust, scale and corrosion products [2,3]. The most commonly-used acids are: hydrochloric acid $(\mathrm{HCl})$, hydrofluoric acid $(\mathrm{HF})$, acetic acid $(\mathrm{CH} 3 \mathrm{COOH})$, formic acid $(\mathrm{HCOOH})$, sulfamic acid $(\mathrm{H} 2 \mathrm{NSO} 3 \mathrm{H})$, and chloroacetic acid $(\mathrm{ClCH} 2 \mathrm{COOH})$. However, choice of the acid for a given situation depends on the underground reservoir characteristics and specific intention of the treatment [4]. In oil fields, $\mathrm{HCl}$ solution is recommended as the cheapest 
way to dissolve calcium carbonate scale inside the pipelines under most conditions [5]. However, $\mathrm{HCl}$ is a strong aggressive (corrosive) medium for oil and gas well equipment. Thus, the effective way to reduce its corrosion attack on tubing and casing materials is to inject a suitable corrosion inhibitor which could be added to the acid solution during the acidization process [4,6-9]. This corrosion control technique is one of the most effective and economic methods for protection of metal corrosion in acidic media, common to the oil industry.

Corrosion inhibition is the most common way of mitigating the internal corrosion in industrial facilities, especially steel-made equipment. There are various types of inhibitors that tend to decrease the corrosion rate of steel and iron in acidic solutions. The use and development of new corrosion inhibitors have been continuously increasing over the years. However, due to environmental restrictions, certain bioorganic and naturally occurring molecules are the most obvious candidates for this type of corrosion inhibitors[10]. Therefore, the biodegradability and nontoxicity degree of a corrosion inhibitor has also become one of the major selection requirements [11]. Amino acids are example of these compounds. They are environmentally friendly [12], nontoxic, relatively very cheap, and easy to produce in purities greater than $99 \%$ [13]. Therefore, the aim of the research presented in this work was to investigate the possibility of using 11-aminoundecanoic acid (AA), Scheme 1, as a corrosion inhibitor for carbon steel in acidic media. AA was previously investigated as a corrosion inhibitor for steel, but in an alkaline solution containing chlorides[14]. In the current work, the corrosion efficiency of $\mathrm{AA}$ was investigated in $\mathrm{HCl}$, as a function of inhibitor concentration, sample exposure time, electrolyte $\mathrm{pH}$ and temperature, and carbon steel surface roughness.

\section{Experimental}

\subsection{Chemicals and solutions}

The corrosion inhibitor, 11-aminoundecanoic; $\mathrm{NH}_{2}\left(\mathrm{CH}_{2}\right){ }_{10} \mathrm{CO}_{2} \mathrm{H}(\mathrm{AA}), 97 \%$ pure, was purchased from Sigma-Aldrich Canada, Ltd (product No. A82605) and was used as received without further purification. Corrosive solutions (electrolytes) containing hydrochloric acid were prepared by diluting concentrated $\mathrm{HCl}(37 \%)$ to a required concentration using deionized water $(18.2 \mathrm{M} \Omega \mathrm{cm}$ resistivity). The inhibitor stock solution was prepared by dissolving the required amount of $A A$ in the corrosive electrolyte.

\subsection{Electrochemical/corrosion cell and equipment}

A standard three-electrode electrochemical/corrosion cell was utilized in all electrochemical experiments. The counter electrode was a graphite electrode. The reference electrode was a saturated calomel electrode (SCE). All potentials in this paper refer to the SCE. The working electrode was prepared from a carbon steel (CS) rod (McMaster-Carr Company Product No. $8920 K 13)$, and sealed with epoxy resin to give a two-dimensional surface $\left(0.713 \mathrm{~cm}^{2}\right)$ exposed to the electrolyte. All the surface-area-dependent values reported in this paper (current, impedance, resistance) are normalized with respect to the geometric surface area of the electrode. The chemical composition of the used CS is given in Table 1.

Electrochemical measurements were performed using an AUTOLAB potentiostat/galvanostat/FRA PGSTAT 30 controlled by FRA2 and GPES v.4.9 software. Chemical identification of the adsorbed AA layer was done by employing polarization modulation infrared absorption reflection spectrometry (PM-IRRAS), using a Bruker FTIR spectrometer, Tensor 27/PM50, equipped with an external polarization-modulation module and liquid nitrogen cooled MCT detector. To 
evaluate the sample surface morphology, scanning electron microscopy (FEG-SEM Phillips XL30) was employed. The surface roughness of the carbon steel surface was measured using DekTak3 ST Surface Profile Measuring System, contact profilometer (Sloan Technology).

Table 1. Chemical composition of carbon steel used in this study. The data were provided by McMaster-Carr Company.

\begin{tabular}{ccccccc}
\hline Element & $\mathrm{Fe}$ & $\mathrm{C}$ & $\mathrm{Mn}$ & $\mathrm{Si}$ & $\mathrm{P}$ & $\mathrm{S}$ \\
\hline Content, wt. \% & Balance & $0.15-0.20$ & $0.60-0.90$ & $0.15-0.30$ & $0-0.04$ & $0-0.05$ \\
\hline
\end{tabular}

\subsection{Experimental methodology}

Prior to each experiment, the working electrode surface was treated with different grit sand papers up to a 4000-grit, to give a mirror-like surface. For the surface roughness studies the CS samples were wet-abraded with different grit sand papers including 240, 320, 400, 600, 2400 and 4000 grits. After each abrasion step, the CS sample was thoroughly rinsed with deionized water. After this, the sample was degreased with ethanol in an ultrasonic bath ( $\sim \mathrm{min}$ ) and then rinsed with deionized water.

The sample (electrode) was then immersed in the test electrolyte and equilibrated for $1 \mathrm{~h}$ at open-circuit potential (OCP), followed by a specific type of experiment. In electrochemical impedance spectroscopy (EIS) measurements, in order to ensure complete characterization of the interface and surface processes, EIS measurements were made at OCP in a wide frequency range, from $100 \mathrm{kHz}$ to $10 \mathrm{mHz}$, with the ac root-mean-square voltage amplitude of $\pm 10 \mathrm{mV}$. Tafel polarization measurements were performed after OCP measurements by polarizing the working electrode from $-200 \mathrm{mV}$ to $+200 \mathrm{mV}$ with respect to measured OCP, at a scan rate of $1 \mathrm{mV} \mathrm{s}{ }^{-1}$. Weight loss measurements were carried out at $295 \mathrm{~K}$ according to the ASTM standard G 31-72 [15]. Strip coupons of dimensions $2.5 \times 2.5 \times 0.3 \mathrm{~cm}$, and a $0.6 \mathrm{~cm}$ diameter hole for mounting by a glass rod, were used. These coupons were kept immersed in the corrosive electrolyte in the absence and presence of different concentrations of AA for $6 \mathrm{~h}$. Before and after each experiment, the CS coupons were dried and weighed using an analytical balance (precision $\pm 0.1 \mathrm{mg}$ ) and the mean weight loss and the corresponding standard deviation is reported in the paper.

All measurements were carried out in oxygen-free solutions, which was achieved by continuous purging of the solution with argon gas (pre-purified grade purity) for at least 30 minutes prior the measurement, and also during the measurement. All the values reported in the paper represent mean values of at least three replicate experiments.

\section{Results and discussion}

\subsection{Effect of inhibitor concentration}

\subsubsection{Electrochemical Impedance Spectroscopy Measurements}

Electrochemical impedance spectroscopy (EIS) technique was applied to investigate the electrode/electrolyte interface and (corrosion) processes that occur on the CS surface in the presence and absence of AA molecules in the electrolyte. Fig. 1 shows an example of EIS spectra in the form of a Nyquist diagram, recorded on a CS electrode in $0.5 \mathrm{M} \mathrm{HCl}$ solution in the absence and presence of $A A$ at different concentrations. The measurements were made after the stabilization of the electrode at OCP for $1 \mathrm{~h}$, and at $295 \mathrm{~K}$. Fig. 1 shows that the diameter of the semicircle increases with the increase in inhibitor concentration in the electrolyte, indicating an increase in corrosion resistance of the material. 


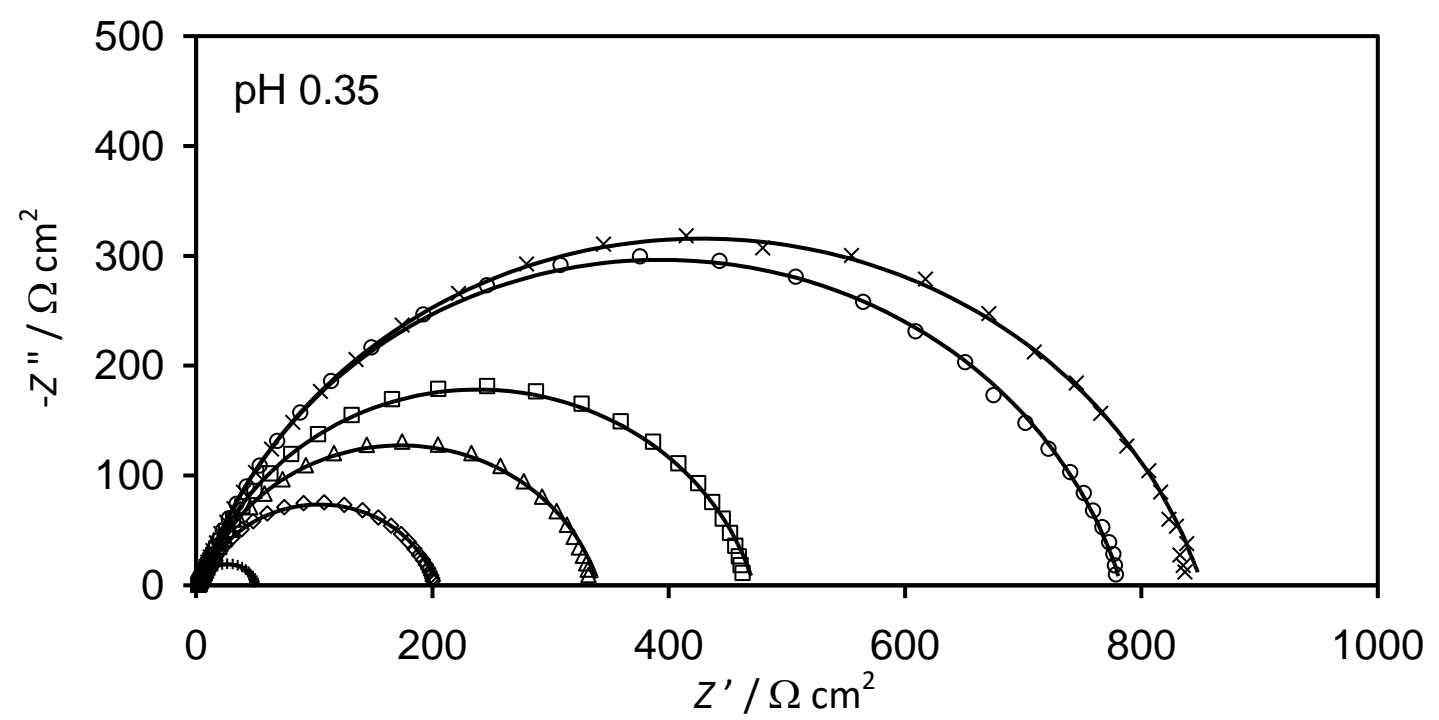

Figure. 1. Nyquist plot of CS recorded at different $A A$ concentrations in $0.5 \mathrm{M} \mathrm{HCl}$ at $295 \mathrm{~K}$. (+) $0 \mathrm{mM},(0) 0.6 \mathrm{mM},(\Delta) 1 \mathrm{mM},(\square) 2 \mathrm{mM},(0) 4 \mathrm{mM}$ and $(x) 6 \mathrm{mM}$ of $A A$. Symbols are experimental data and solid lines represent the simulated (modeled) spectra

In order to extract qualitative information, a nonlinear least-squares (NLLS) fit analysis was used to model the spectra, employing the electrical equivalent circuits (EECs) presented in Fig. 2. In these EECS, $R_{\mathrm{el}}$ represents the ohmic resistance between the working and the reference electrode; $R_{1}$ is the charge transfer resistance related to the corrosion reaction at OCP; CPE 1 is the capacitance of the electric double-layer at the electrode/electrolyte interface; $R_{2}$ can be prescribed to the pseudo-resistance of the surface-adsorbed AA layer (i.e. the combined resistance of the electro-active species diffusion and the electrolyte resistance in 'pores'), while the element $C P E_{2}$ is its pseudo-capacitance. Thus, the corrosion resistance of CS in the presence of AA represents the $R_{1}+R_{2}$ sum. In the absence of AA (control sample), the spectra was modeled using the one-time constant EEC, Fig. 2a, in which the CS corrosion resistance is represented by $R_{1}$. CPE's are often used to describe a non-ideal capacitive behaviour due to different factors such as surface roughness and heterogeneities or a non-uniform potential and current distribution[16]. The impedance of a CPE is given as $Z_{C P E}=Q^{-1}(j \omega)^{-n}$, where $Z$ is the CPE impedance $\left(\Omega \mathrm{cm}^{2}\right), Q$ is a constant with units $\Omega^{-1} \mathrm{~cm}^{-2} \mathrm{~s}^{n}, n$ is a dimensionless constant in the range $-1 \leq n \leq 1, j$ is the imaginary number $j=(-1)^{0.5}$ and $\omega$ is the angular frequency ( $\omega=2 \pi f, f$ being the frequency). An ideal capacitor behaviour yields $n=1$, a resistor yields $n=0$ and an inductor yields $n=-1$, while $n=0.5$ represents the response of mass-transport processes.

Fig. 1 demonstrates that excellent agreement between the experimental data (symbols) and the model (lines) is obtained, justifying the use of the proposed EECs. The corrosion resistance values are presented in Table 2 along with the corrosion inhibition efficiency of AA, $\eta$, which was calculated by comparing the total resistance value, $R_{\mathrm{i}}=R_{1}+R_{2}\left(\Omega \mathrm{cm}^{2}\right)$, recorded at various concentrations of AA in the electrolyte, and the $R_{0}$ value recorded in the absence of AA (control sample) [17]:

$$
\eta_{\mathrm{i}} / \%=\left(1-\frac{R_{0}}{R_{\mathrm{i}}}\right) 100
$$

$R_{\mathrm{i}}$ and $\eta_{\mathrm{i}}$ values together with the corresponding standard deviation are listed in Table 2, while Fig. 3 illustrates the concentration dependence of the AA corrosion inhibition efficiency. With an 
increase in the inhibitor concentration in the bulk solution, the corrosion inhibition efficiency also increases, and levels off into a plateau, reaching a value of ca. $95 \%$. The trend in corrosion inhibition efficiency could be related to the surface coverage and different orientation of the inhibitor molecule on the surface. Namely, with an increase in inhibitor concentration in the solution, its surface concentration also increases, but at low AA concentrations in the solution a highly disordered amorphous AA sub-monolayer is formed on the CS surface. This layer is still 'porous' and enables interaction of the corrosive electrolyte with the CS surface. However, with a further increase in the inhibitor concentration in the solution, the surface concentration, coverage and order of the AA monolayer increases, thus offering a tighter hydrophobic barrier (due to the presence of the long $-\mathrm{CH}_{2}$ chain) for the penetration of solvated aggressive ions to the underlying surface.

(a)

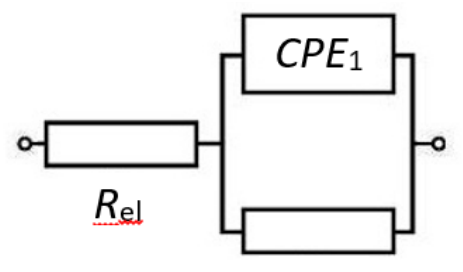

$R_{1}$

(b)

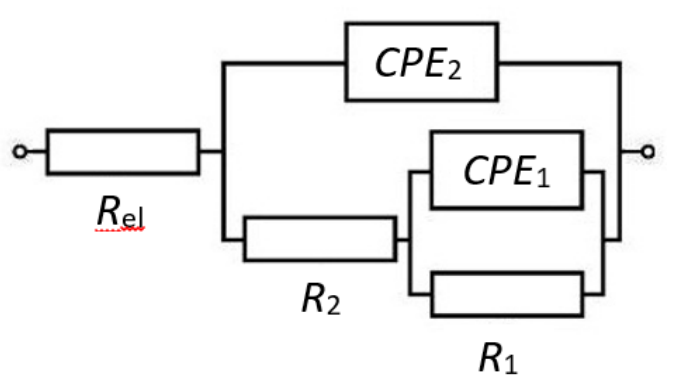

Figure 2. EEC models used to fit EIS data recorded on (a) a bare CS electrode (control sample), and (b) on a CS electrode immersed in an electrolyte containing $A A$

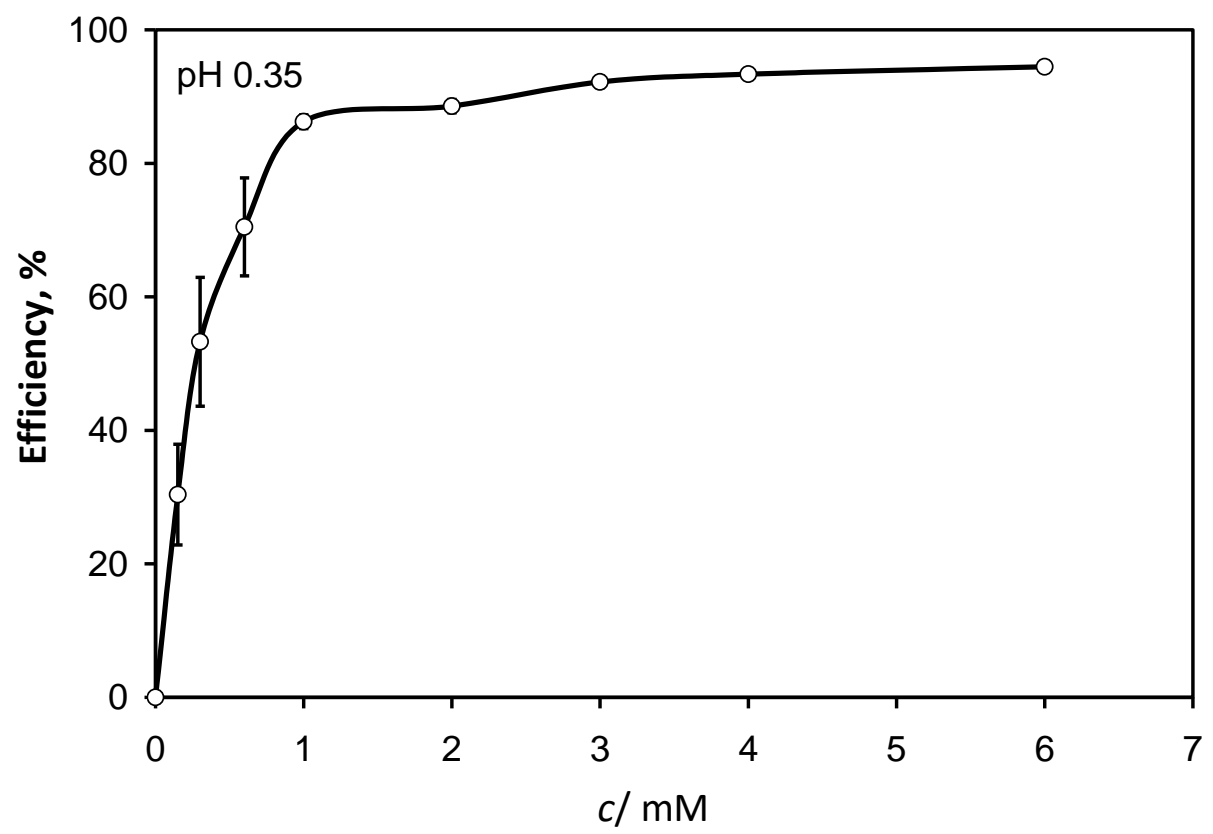

Figure 3. Corrosion inhibition efficiency of $A A$ in protecting CS from general corrosion in $0.5 \mathrm{M} \mathrm{HCl}$ solution at $295 \mathrm{~K}$. The data represent mean values obtained from EIS measurements, performed at various concentrations of $A A$, while the error bars represent the corresponding standard deviation (note that at higher AA concentrations, the corresponding standard deviation is rather small) 
Table 2 Dependence of EEC parameters on the concentration of $A A$ in the electrolyte.

The data were obtained by modeling the EIS spectra recorded in $0.5 \mathrm{M} \mathrm{HCl}$ and at $295 \mathrm{~K}$.

The data also lists the corresponding corrosion inhibition efficiency values, $\eta_{\text {i. }}$.

Quantity $n$ represents $S D=$ standard deviation. An average electrolyte resistance value was $4 \pm 2 \Omega$

\begin{tabular}{cccccccccc}
\hline$c_{\mathrm{i}} / \mathrm{mM}$ & 0 & 0.15 & 0.3 & 0.6 & 1 & 2 & 3 & 4 & 6 \\
\hline$C P E_{1} \times 10^{6} / \Omega^{-1} \mathrm{~cm}^{-2} \mathrm{~s}^{\mathrm{n}}$ & 652 & 645 & 175 & 111 & 39 & 43 & 102 & 29 & 19 \\
$\pm \mathrm{SD}$ & 89 & 1 & 41 & 18 & 11 & 5 & 59 & 13 & 6 \\
\hline$n_{1}$ & 0.83 & 0.8 & 0.81 & 0.81 & 0.83 & 0.82 & 0.74 & 0.78 & 0.81 \\
$\pm \mathrm{SD}$ & 0.02 & 0 & 0 & 0 & 0 & 0 & 0.09 & 0.08 & 0.02 \\
\hline$R_{1} / \Omega \mathrm{cm}^{2}$ & 50 & 70 & 107 & 167 & 311 & 407 & 578 & 722 & 840 \\
$\pm \mathrm{SD}$ & 2 & 5 & 18 & 31 & 1 & 31 & 84 & 42 & 62 \\
\hline$C P E_{2} \times 10^{6} / \Omega^{-1} \mathrm{~cm}^{-2} \mathrm{~s}^{\mathrm{n}}$ & - & 423 & 167 & 160 & 94 & 91 & 71 & 79 & 82 \\
$\pm \mathrm{SD}$ & - & 21 & 39 & 8 & 6 & 21 & 24 & 8 & 8 \\
\hline$n_{2}$ & - & 0.82 & 0.85 & 0.82 & 0.83 & 0.82 & 0.88 & 0.83 & 0.82 \\
$\pm \mathrm{SD}$ & - & 0 & 0 & 0.03 & 0.01 & 0.02 & 0.02 & 0.01 & 0.01 \\
\hline$R_{2} / \Omega \mathrm{cm}^{2}$ & - & 3 & 3 & 9 & 57 & 35 & 37 & 58 & 82 \\
$\pm \mathrm{SD}$ & - & 1 & 1 & 6 & 41 & 6 & 14 & 5 & 40 \\
\hline$R_{\mathrm{i}} / \Omega \mathrm{cm}^{2}$ & 50 & 73 & 110 & 176 & 368 & 442 & 615 & 780 & 922 \\
$\pm \mathrm{SD}$ & 2 & 5 & 18 & 37 & 42 & 26 & 92 & 39 & 103 \\
\hline$\eta_{\mathrm{i}} / \%$ & 0 & 30 & 53 & 71 & 86 & 89 & 92 & 93 & 95 \\
$\pm \mathrm{SD}$ & 0 & 8 & 10 & 7 & 1 & 1 & 1 & 1 & 1 \\
\hline & & & & & & & & &
\end{tabular}

\subsubsection{Adsorption isotherm}

From the previous discussion it is obvious that the AA corrosion inhibition efficiency depends on its surface concentration. Thus, the mechanism of interaction of AA with the CS surface is of adsorptive type. In order to describe adsorption of AA on the CS surface, several adsorption isotherms were tested. However, the best agreement was obtained using the Langmuir adsorption isotherm $[17,18]$ :

$$
\Gamma=\frac{B_{\mathrm{ads}} \Gamma_{\max } c}{1+B_{\mathrm{ads}} c}
$$

where $c / \mathrm{mol} \mathrm{cm}^{-3}$ is the equilibrium concentration of $A A$ in the bulk solution, $\Gamma / \mathrm{mol} \mathrm{cm}^{-2}$ is its amount adsorbed onto the surface (i.e. its surface concentration), $\Gamma_{\max } / \mathrm{mol} \mathrm{cm}^{-2}$ is the maximum value of $\Gamma$, and the parameter $B_{\text {ads }}\left(\mathrm{cm}^{3} \mathrm{~mol}^{-1}\right)$ reflects the affinity of the inhibitor molecules towards surface adsorption sites. The surface coverage at a particular AA surface concentration could be expressed as $\theta=\Gamma / \Gamma_{\max }$. Thus, Eq.(2) can be rearranged to give [17,19-21]:

$$
\frac{c}{\theta}=\frac{1}{B_{\mathrm{ads}}}+c
$$

Consequently, if the Langmuir isotherm describes the inhibitor adsorption process, a plot of experimental data expressed as $c / \theta$ vs. $c$ should yield a straight line with a slope of one. Assuming that the inhibition efficiency, $\eta$, is proportional to the inhibitor surface coverage, $\theta[22]$, the mean 
corrosion inhibition efficiency values obtained using EIS technique (Fig. 3) are presented in Fig. 4 in a form of the linearized Langmuir isotherm (Eq.(3)). The agreement between the Langmuir isotherm and experimental data is very good $\left(R^{2}=0.9992\right)$. The corresponding slope $(1.01)$ is very close to the theoretical value of one. Therefore, it could be deemed that the adsorption of $A A$ on the CS surface indeed follows the Langmuir isotherm.

The intercept of the line in Fig. 4 yielded $B_{\text {ads }}=3.93 \times 10^{3} \mathrm{dm}^{3} \mathrm{~mol}^{-1}$, and the corresponding apparent Gibbs free energy of adsorption was then calculated from [18-20,22,23]

$$
B_{\text {ads }}=\frac{1}{C_{\text {solvent }}} \exp \left(\frac{-\Delta G_{\text {ads }}}{R T}\right)
$$

where $R / \mathrm{J} \mathrm{mol}^{-1} \mathrm{~K}^{-1}$ is the gas constant, $T / \mathrm{K}$ is the temperature, and $c_{\text {solvent }}$ is the molar concentration of the solvent, which in this case, is water $\left(C_{\mathrm{H}_{2} \mathrm{O}}=55.5 \mathrm{~mol} \mathrm{dm}{ }^{-3}\right)$. Using this equation, the apparent Gibbs free energy of adsorption of AA on the CS surface at $295 \mathrm{~K}$ was calculated to be $-30.2 \mathrm{~kJ} \mathrm{~mol}^{-1}$ (values of -31.5 and $-33.7 \mathrm{~kJ} \mathrm{~mol}^{-1}$ were obtained from Tafel and weight-loss measurements presented later in the paper, respectively, yielding an average Gibbs free energy of adsorption value of $-32 \pm 2 \mathrm{~kJ} \mathrm{~mol}^{-1}$ ). This highly negative value demonstrates that the $A A$ adsorption process is highly spontaneous $[2,3,24,25]$.

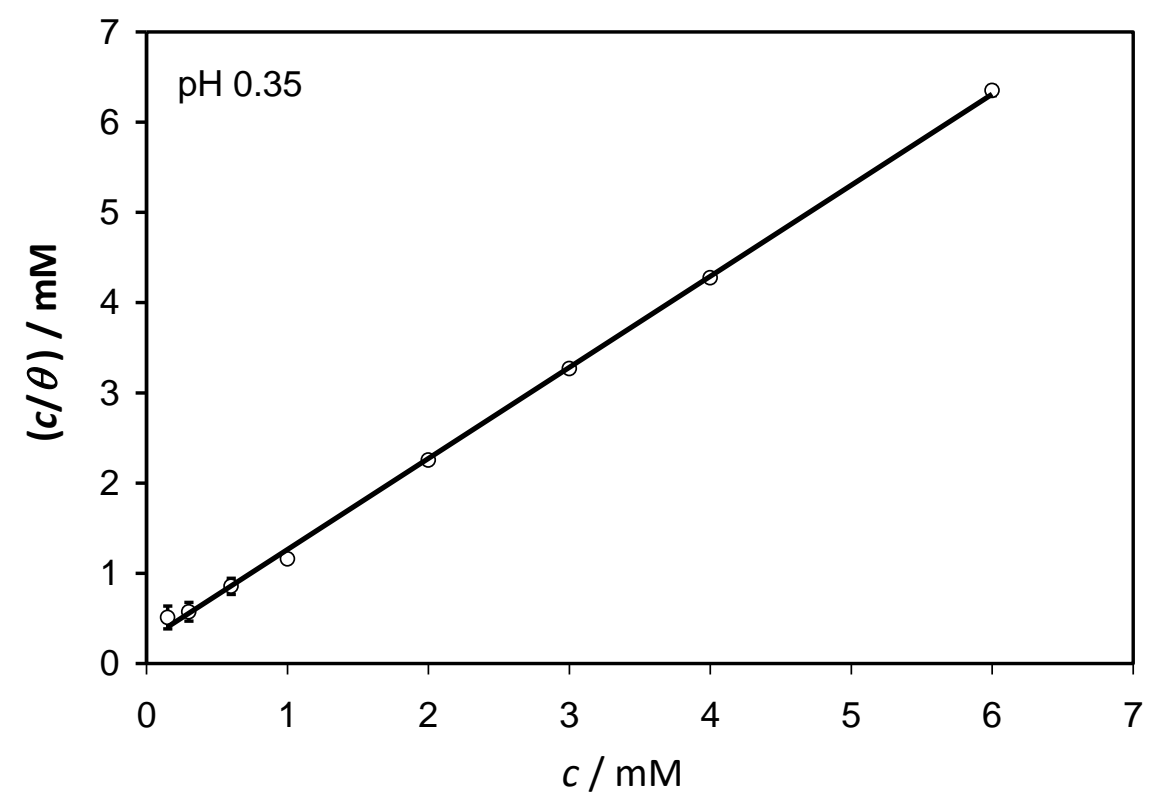

Figure 4. Linearized form of the Langmuir adsorption isotherm for adsorption of $A A$ onto the $C S$ surface at $295 \mathrm{~K}$. The data was obtained from EIS measurements

We further investigated whether AA molecules are physic- or chemisorbed on the CS surface, by performing PM-IRRAS measurements (Fig. 5). In these measurement, the CS sample was left in the AA-containing solution for three days, then removed from solution, rinsed very well, dried and finally scanned by PM-IRRAS. The presence of the two peaks at $2853 \mathrm{~cm}^{-1}$ and $2926 \mathrm{~cm}^{-1}$, Figure 5, demonstrate the presence of $A A$ on the surface, since these correspond to the symmetric and asymmetric $\mathrm{C}-\mathrm{H}$ stretching vibrations of the $-\mathrm{CH}_{2}$ groups in the $\mathrm{AA}$ chain, respectively [26,27]. If $A A$ molecules were only physisorbed on the CS surface, the thorough rinsing performed after pulling out the samples from the AA-containing solution would have removed the molecules and no IR absorption peaks would have been recorded. However, the wavenumber position of the $\mathrm{CH}_{2}$ asymmetric peak in Fig. $5\left(2926 \mathrm{~cm}^{-1}\right)$ indicates that the AA SAM has a rather amorphous structure (a perfectly ordered SAM would give $2918 \mathrm{~cm}^{-1}$ ) [28]. This could be attributed to the 
repulsion between the neighboring positively charged amine groups and a high heterogeneity of the CS surface.

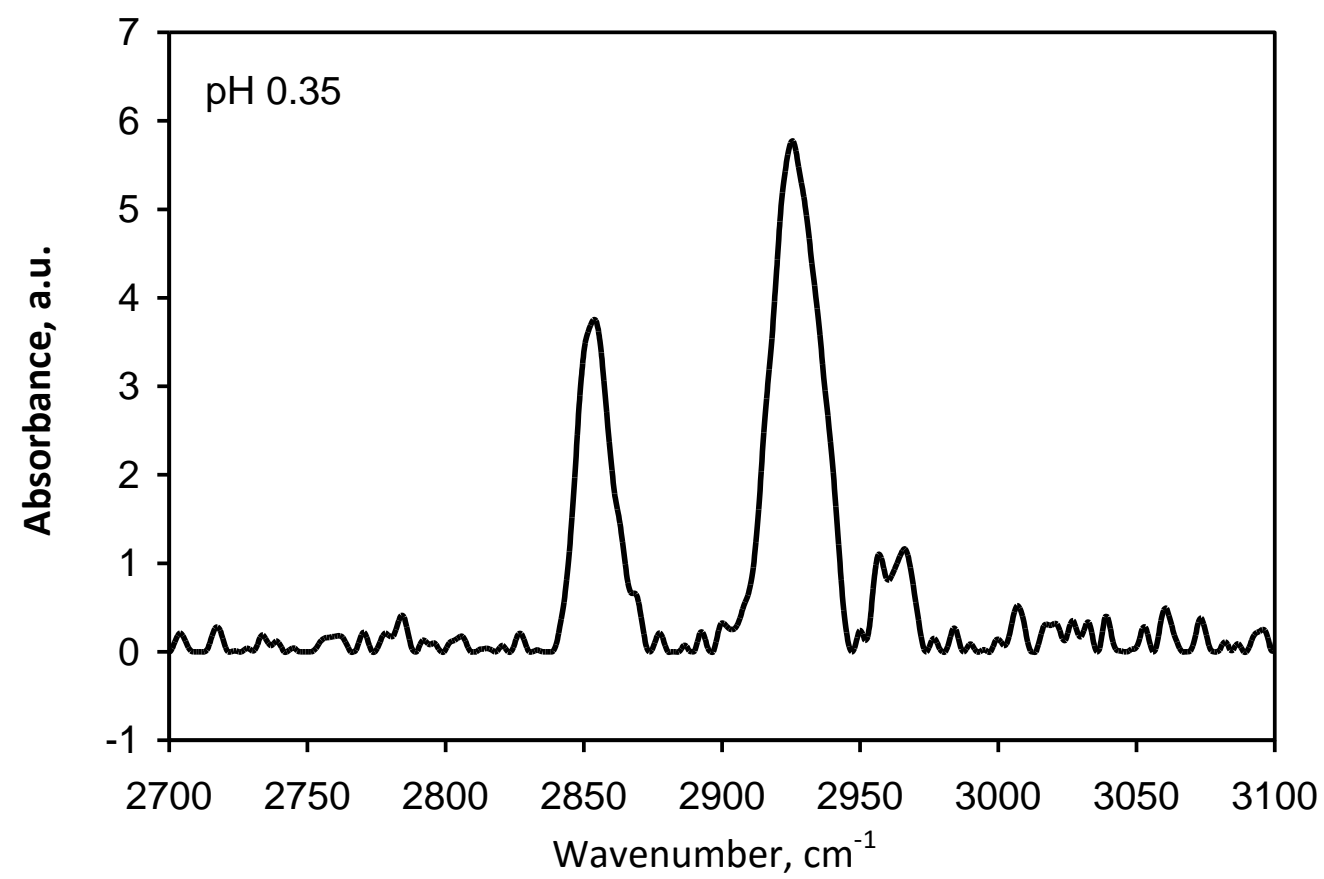

Figure 5. PM-IRRAS spectra of the AA SAM on a CS substrate. The spectra were recorded at OCP after 3 days of immersing the CS sample in $0.5 \mathrm{M} \mathrm{HCl}$ containing $3 \mathrm{mM}$ of $A A$ at $295 \mathrm{~K}$

\subsubsection{Tafel polarization measurements}

Tafel polarization measurements were made to complement/verify the data obtained from EIS measurements. Fig. 6 shows Tafel curves recorded on a CS electrode in $0.5 \mathrm{M} \mathrm{HCl}$, in the absence of $A A$ (control) and at various concentrations of $A A$ in the electrolyte. Under the experimental conditions performed, the cathodic branch represents the hydrogen evolution reaction, while the anodic branch represents the iron dissolution reaction.

From Fig. 6 it is clear that with an increase in concentration of AA in the bulk solution, both the cathodic and anodic current decreases. This indicates that AA acts as a mixed-type corrosion inhibitor. Also, there is a slight shift in the corrosion potential to the negative direction which indicates a slightly stronger cathodic inhibition than anodic inhibition of the dissolution. The corresponding corrosion current densities $\left(j_{\text {corr }}\right)$ were estimated by the extrapolation of the linear part of the cathodic and anodic curves to the corrosion potential, and presented in Table 3 (mean value) together with the corresponding inhibition efficiency, which was calculated using the following equation $[5,13,17,29,30]$ :

$$
\eta_{\mathrm{i}} / \%=\left(1-\frac{j_{\text {corr }, \mathrm{i}}}{j_{\mathrm{corr}, \mathrm{o}}}\right) 100
$$

where $j_{\text {corr, }} / \mathrm{A} \mathrm{cm}^{-2}$ is the corrosion current density at a particular AA concentration, and $j_{\text {corr, } 0}$ is the corrosion current density in the absence of AA in the solution. It can be seen from Table 3 that the dependence of corrosion inhibition efficiency on the AA concentration is very similar to that obtained from EIS measurements (Table 2). Consequently, these results can be explained in 
the same way previously done in the EIS section and, therefore; provide a good agreement between the two different techniques.

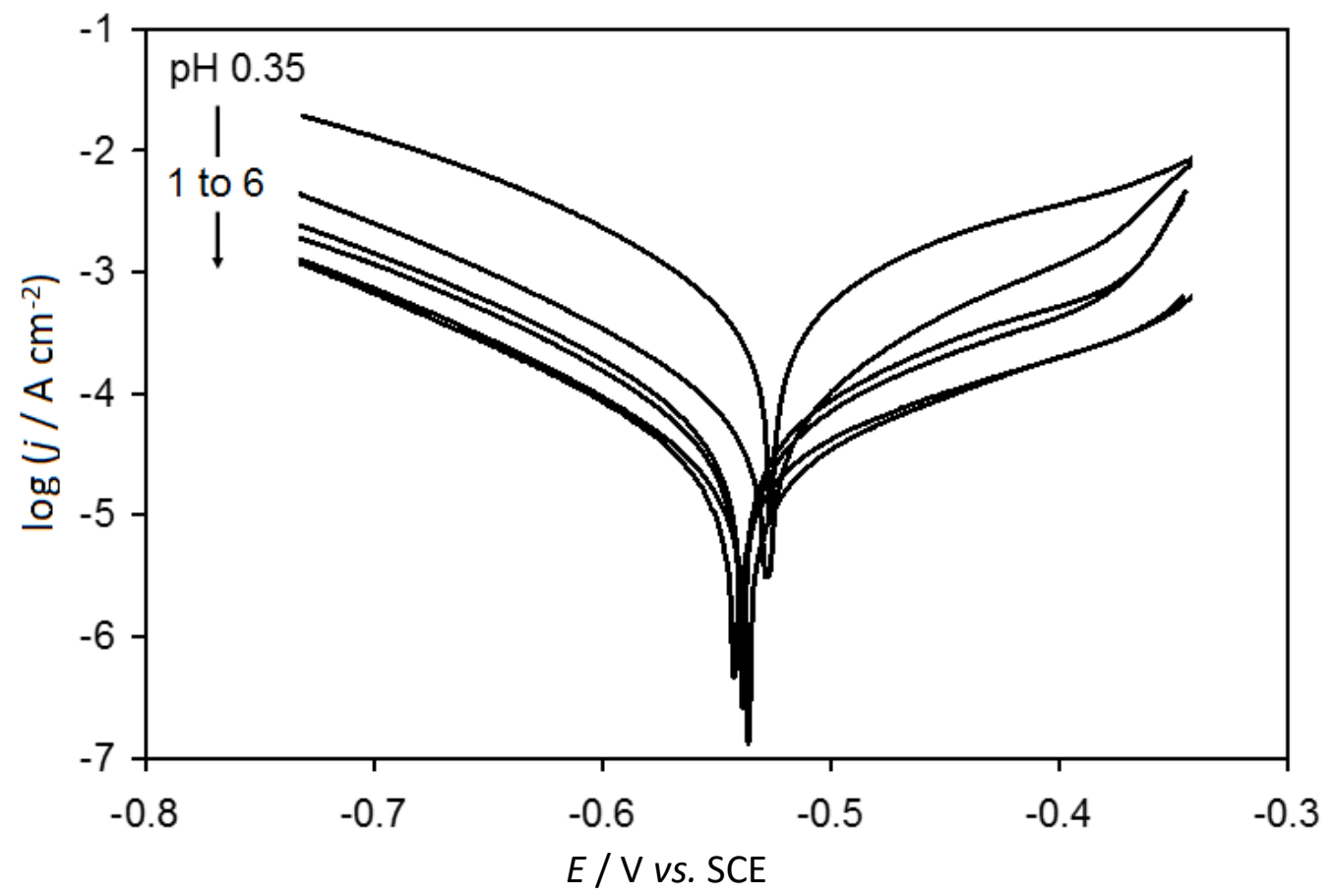

Figure 6. Tafel plots of the CS recorded at various concentrations of $A A$ in $0.5 \mathrm{M} \mathrm{HCl}$ at $295 \mathrm{~K}$. (1) $0 \mathrm{mM}$, (2) $0.3 \mathrm{mM}$, (3) $1 \mathrm{mM}$, (4) $2 \mathrm{mM}$, (5) $4 \mathrm{mM}$, and (6) $6 \mathrm{mM}$ AA. Scan rate $=1 \mathrm{mV} \mathrm{s}^{-1}$

Table 3. Corrosion current density $\left(j_{\text {corr, }}\right)$ calculated form Tafel measurements recorded on CS in $0.5 \mathrm{M} \mathrm{HCl}$ solution containing various concentrations of $A A$ at $295 \mathrm{~K}$. The data also lists the corresponding corrosion inhibition efficiency values, $\eta_{i} . S D=$ standard deviation

\begin{tabular}{lccccccccc}
\hline$c_{\mathrm{i}} / \mathrm{mM}$ & 0 & 0.15 & 0.3 & 0.6 & 1 & 2 & 3 & 4 & 6 \\
\hline$j_{\text {corr,i }} / \mu \mathrm{A} \mathrm{cm}^{-2}$ & 528 & 350 & 221 & 111 & 42 & 41 & 24 & 24 & 25 \\
$\pm \mathrm{SD}$ & 30 & 9 & 25 & 47 & 13 & 5 & 2 & 2 & 4 \\
\hline$\eta_{\mathrm{i}} / \%$ & 0 & 39 & 62 & 81 & 92 & 92 & 95 & 95 & 95 \\
$\pm \mathrm{SD}$ & 0 & 2 & 2 & 7 & 3 & 1 & 1 & 1 & 2 \\
\hline
\end{tabular}

\subsubsection{Weight-loss measurements}

Weight loss measurements were carried out at $295 \mathrm{~K}$ in $0.5 \mathrm{M} \mathrm{HCl}$ solution, in the absence and presence of various concentrations of AA. Table 4 reports the values of corrosion rate $(C R)$ and the corresponding corrosion inhibition efficiency $(\eta)$ at various concentrations of AA. The corrosion rate $(C R$, millimeters per year) was calculated from the following relation [15]:

$$
C R=\frac{K W}{A \rho t}
$$

where $t$ is the specimen immersion time (h), $A$ is the surface area of the test specimen $\left(\mathrm{cm}^{2}\right), W$ is the weight loss $(\mathrm{g}), \rho$ is the density of the test specimen $(\mathrm{g}) \mathrm{cm}^{-3}$, and $K=8.76 \times 10^{4}$ is the conversion constant that enables expressing $C R$ in millimeters per year when $t, A, W$ and $\rho$ values are expressed in the quoted units. Table 4 shows that with an increase in AA concentration in the bulk electrolyte, the corrosion rate decreases. In order to better quantify this, the corrosion inhibition efficiency was calculated from [31]: 


$$
\eta_{\mathrm{i}} / \%=\left(1-\frac{W_{\mathrm{i}}}{W_{0}}\right) 100
$$

where $W_{0}$ and $W_{i}$ are the weight loss, g of the test specimen in the absence and presence of the inhibitor at a specified concentration (i), respectively. The $\eta_{\mathrm{i}}$ values in Table 4 demonstrate a significant increase in inhibition efficiency with the AA concentration increase. It can be noticed from Table 4 that the results are very similar to those obtained from EIS and Tafel measurements (Tables 2 and 3 ), and could be explained in the same way.

Table 4 Data obtained from weight-loss measurements of carbon steel immersed $6 \mathrm{~h}$ in $0.5 \mathrm{M} \mathrm{HCl}$ solution in the absence and presence of various concentrations of AA at $295 \mathrm{~K} . S D=$ standard deviation

\begin{tabular}{lccccccccc}
\hline$c_{\mathrm{i}} / \mathrm{mM}$ & 0 & 0.15 & 0.3 & 0.6 & 1 & 2 & 3 & 4 & 6 \\
\hline$W_{\mathrm{i}} / \mathrm{mg} \mathrm{cm}^{-2}$ & 1.10 & 0.30 & 0.14 & 0.12 & 0.08 & 0.06 & 0.06 & 0.04 & 0.03 \\
$\pm \mathrm{SD}$ & 0.16 & 0.02 & 0.02 & 0.02 & 0.01 & 0.01 & 0 & 0.01 & 0 \\
\hline$C R / \mathrm{mm} \mathrm{y}^{-1}$ & 2.04 & 0.57 & 0.27 & 0.22 & 0.16 & 0.10 & 0.12 & 0.08 & 0.05 \\
$\pm \mathrm{SD}$ & 0.30 & 0.04 & 0.04 & 0.04 & 0.01 & 0.02 & 0.01 & 0.02 & 0.01 \\
\hline$\eta_{\mathrm{i}} / \%$ & 0 & 72 & 87 & 89 & 92 & 94.9 & 94.5 & 96 & 97 \\
$\pm \mathrm{SD}$ & 0 & 5 & 2 & 2 & 1 & 0.2 & 0.3 & 1 & 1 \\
\hline
\end{tabular}

\subsection{Effect of time}

In order to investigate the AA adsorption kinetics, to determine the time needed for AA to yield the maximum inhibition efficiency at the given conditions, and to investigate the longer-term inhibitor efficiency, EIS experiments and Tafel experiments in the absence and presence of $3 \mathrm{mM}$ of $A A$ in $0.5 \mathrm{M} \mathrm{HCl}, \mathrm{pH} 0.35$, were made at selected time intervals, at OCP. The corrosion inhibition efficiency values were calculated and presented in Fig. 7.

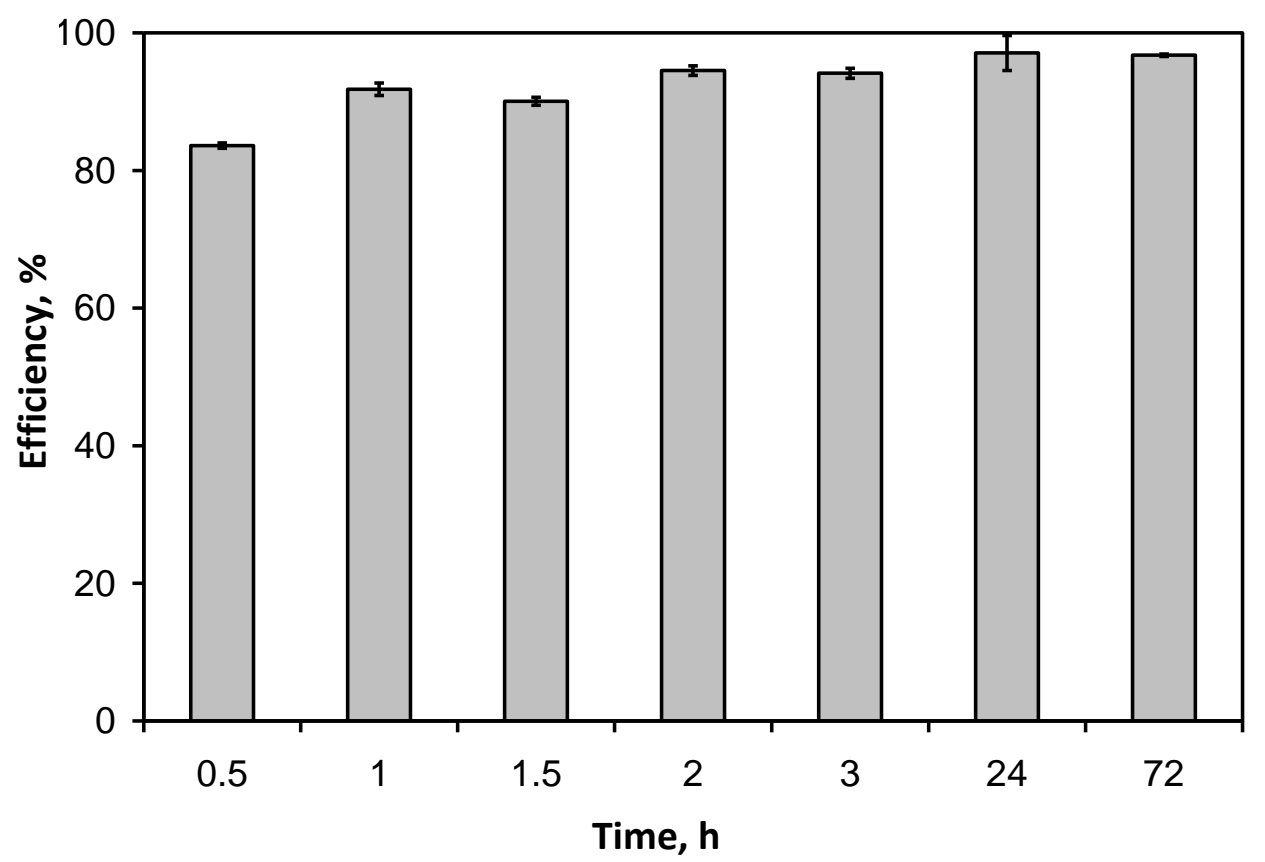

Figure 7. Dependence of the corrosion inhibition efficiency on the immersion time obtained from EIS measurements recorded on CS in the absence and presence of $3 \mathrm{mM}$ of $A A$ in $0.5 \mathrm{M} \mathrm{HCl}$ at $295 \mathrm{~K}$ 
The plot shows that an improvement in the corrosion inhibition efficiency is obtained with increasing immersion time. This can be, in the first approximation, associated with the kinetics of $A A$ adsorption on the CS surface, and with the re-arrangement of the formed AA layer to achieve higher surface order, and thus better corrosion protection. A high inhibition efficiency was reached after $1 \mathrm{~h}$, and remained high even after 3 days of testing (97\%). Thus, it can be concluded that $A A$ is a very efficient long-term action corrosion inhibitor for $C S$, under the experimental conditions investigated.

\subsection{Effect of Surface Roughness}

In order to study the influence of surface roughness on the corrosion inhibition efficiency, EIS, Tafel and weight-loss measurements were made on CS surfaces abraded with different sand paper grit numbers: 240, 320, 400, 600, 2400 and 4000 in the absence and presence of 3 mM of AA in 0.5 $\mathrm{M} \mathrm{HCl}$ solution. The surface roughness of each fresh abraded sample were quantitatively evaluated using surface profilometery. A series of profile line-scans were performed and the corresponding average roughness values were calculated and presented in Table 5 . Using the same procedure that was described earlier in the text, the corrosion inhibition efficiency values were calculated and presented in Fig. 8.

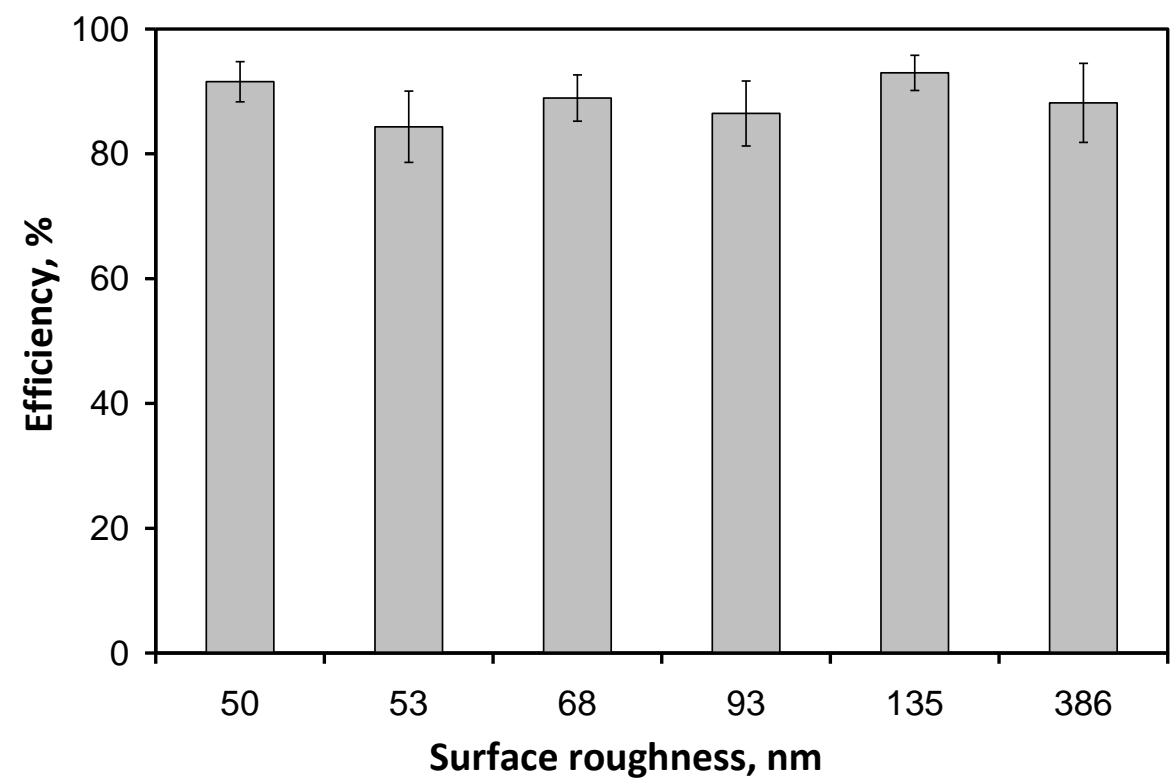

Figure 8. Dependence of corrosion inhibition efficiency on CS surface roughness obtained from EIS, Tafel and weight-loss measurements recorded on CS in the absence and presence of $3 \mathrm{mM}$ of $A A$ in $0.5 \mathrm{M} \mathrm{HCl}$ at $295 \mathrm{~K}$

It can be seen from Fig. 8 that the inhibitor shows a similar effect and there is no significant difference in its effect at all different surfaces studied. This indicates a good affinity of AA molecules to adsorb on the CS surface of different roughness. The inhibition effect can be more clearly seen from Fig. 9 which shows the CS surface topography for a freshly-abraded sample using 2400 sand paper and also after 3 days of immersion in the testing electrolyte in the absence and presence of AA. Fig. 9b demonstrates that the CS surface is extensive and highly damaged. On the other hand, in the presence of $3 \mathrm{mM}$ of AA in the solution (Fig. 9c), the surface topography is similar to the fresh (non-corroded) sample (Fig. 9a), evidencing that the CS surface corroded only negligibly in the presence of AA. Similar observations were found when the surfaces were abraded using other sand papers. 
Table 5 Average surface roughness of CS samples prepared using emery paper of various grits $S D=$ standard deviation

\begin{tabular}{lcccccc}
\hline Grit number & 240 & 320 & 400 & 600 & 2400 & 4000 \\
\hline Surface roughness, $\mathrm{nm}$ & 386 & 135 & 93 & 68 & 53 & 50 \\
\hline$\pm \mathrm{SD}$ & 16 & 2 & 2 & 1 & 1 & 1 \\
\hline
\end{tabular}

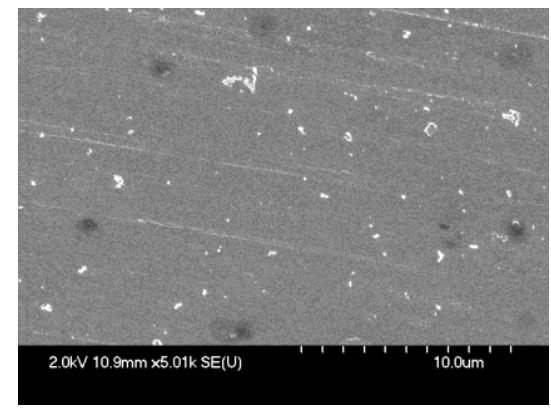

(a)

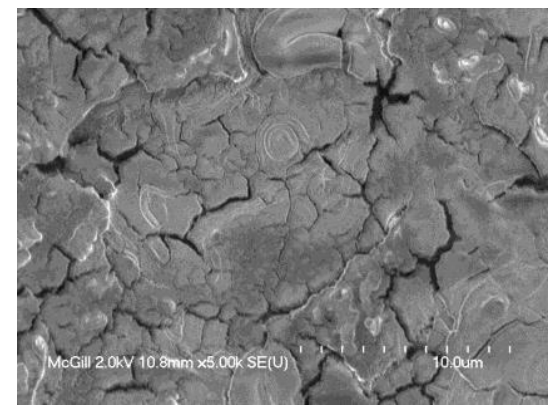

(b)

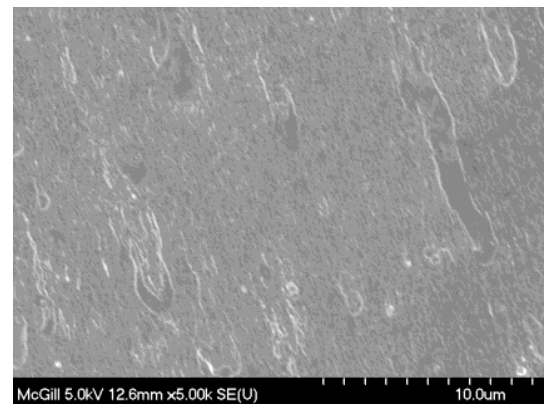

(c)

Figure 9. SEM images of CS surfaces prepared using 2400 grit paper. (a) fresh abraded sample, (b) after 3 days of immersion in the absence and (c) in the presence of $3 \mathrm{mM}$ of $A A$ in $0.5 \mathrm{M} \mathrm{HCl}$ solution at $295 \mathrm{~K}$.

All images have been taken at the same magnification, and the corresponding length bar is $10 \mu \mathrm{m}$

\subsection{Effect of temperature}

The effect of temperature on the inhibition effect of AA on carbon steel corrosion was studied over a wide temperature range, from $295 \mathrm{~K}$ to $323 \mathrm{~K}$. In this study, EIS measurements were carried out by using different AA concentrations from $0 \mathrm{mM}$ to $3 \mathrm{mM} \mathrm{AA}$. Fig. 10a shows a set of EIS spectra recorded at different temperatures in the absence of $A A$ in the solution. With an increase in temperature, the diameter of the semicircle decreases, i.e. the charge-transfer resistance decreases, which is due to the increased corrosion rate. This is a typical behavior, since with an increase in temperature, the corrosion reaction kinetics also increases, and thus the corrosion rate. Quite the same behaviour was observed in the presence of AA in the solution (Fig. 10b). However, by comparing the charge-transfer values at a fixed temperature, it is obvious that AA acts as a good corrosion inhibitor in the whole temperature range.

EIS spectra at all investigated temperatures (example in Fig. 10) were treated in the same way in the Section 3.1.1 and the corrosion inhibition efficiency were evaluated at different concentration of AA, Fig. 11. The data shows that the corrosion efficiency of the inhibitor remains almost constant in the whole temperature range, which indicates that the AA molecule is chemically stable in the investigated temperature range, and that the mechanism of its corrosion inhibition does not change. Hence, AA seems to be a good inhibitor candidate even at higher temperatures.

Further, the EIS data was treated in the same way as in Fig. 3 and Fig. 4 to find apparent Gibbs free energy of adsorption at different temperatures, $\Delta G_{\text {ads, }}$ which were calculated, and presented in Fig. 12. Subsequently, taking that:

$$
\Delta G_{\mathrm{ads}}=\Delta H_{\mathrm{ads}}-T \Delta S_{\mathrm{ads}}
$$

the enthalpy and entropy of adsorption was calculated to be $\Delta H_{\text {ads }}=36.6 \mathrm{~kJ} \mathrm{~mol}^{-1}$, and $\Delta S_{\text {ads }}=230 \mathrm{~J} \mathrm{~mol}^{-1} \mathrm{~K}^{-1}$, respectively. The enthalpy value demonstrates that the adsorption of AA on the CS surface is endothermic. Nevertheless, the relatively high negative Gibbs free energy values (Fig. 12) demonstrate that the overall adsorption process is highly spontaneous. Therefore, the 
major contribution to this spontaneity has to come from a positive gain in entropy. This gain seems to be the main contributor to the driving force for the adsorption of AA on CS. This can be explained with that the major contribution to the entropy gain in the system comes from the loss of the order of water molecules adsorbed on the CS surface upon AA adsorption. Under the influence of the electric charge on the CS surface, the adsorbed water molecules are highly ordered on the electrode surface [32], but when displaced by AA molecules, this high degree of order significantly decreases due to the random orientation of the displaced molecules in the bulk solution. This results in an overall increase in the positional degree of freedom of the system, i.e. an entropy gain. On the other hand, adsorbed AA molecules lose positional degrees of freedom, but this effect is largely overcome by the positive entropy contribution coming from water.
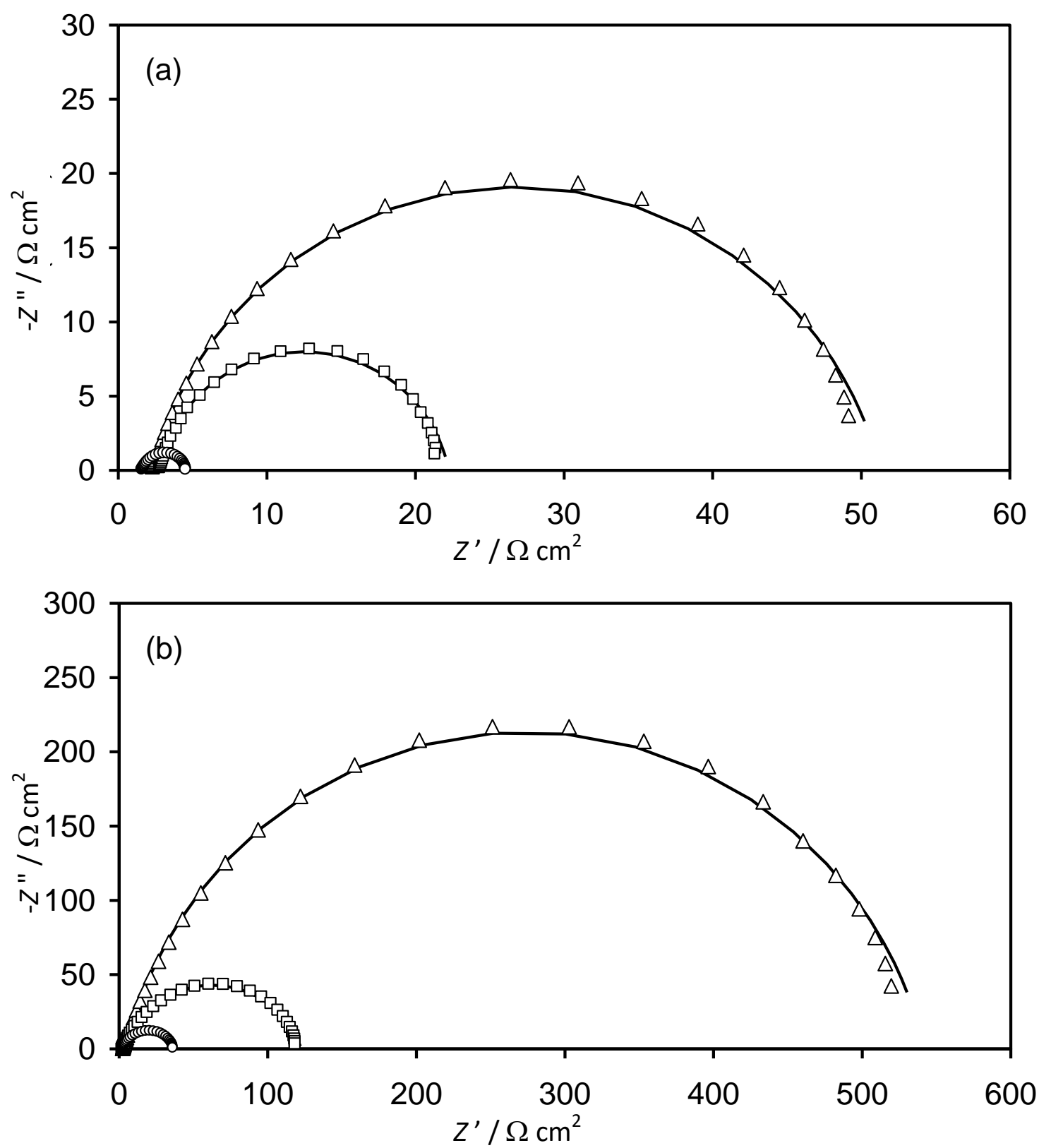

Figure 10. Nyquist impedance plots for carbon steel recorded at different temperatures

$(\Delta) 295 \mathrm{~K},(\square) 308 \mathrm{~K}$, and (O) $323 \mathrm{~K}(\mathrm{a})$ in the absence, and (b) presence of $3 \mathrm{mM}$ of $\mathrm{AA}$ in $0.5 \mathrm{mM} \mathrm{HCl}$.

Symbols are experimental data and solid lines represent the simulated (modeled) spectra 


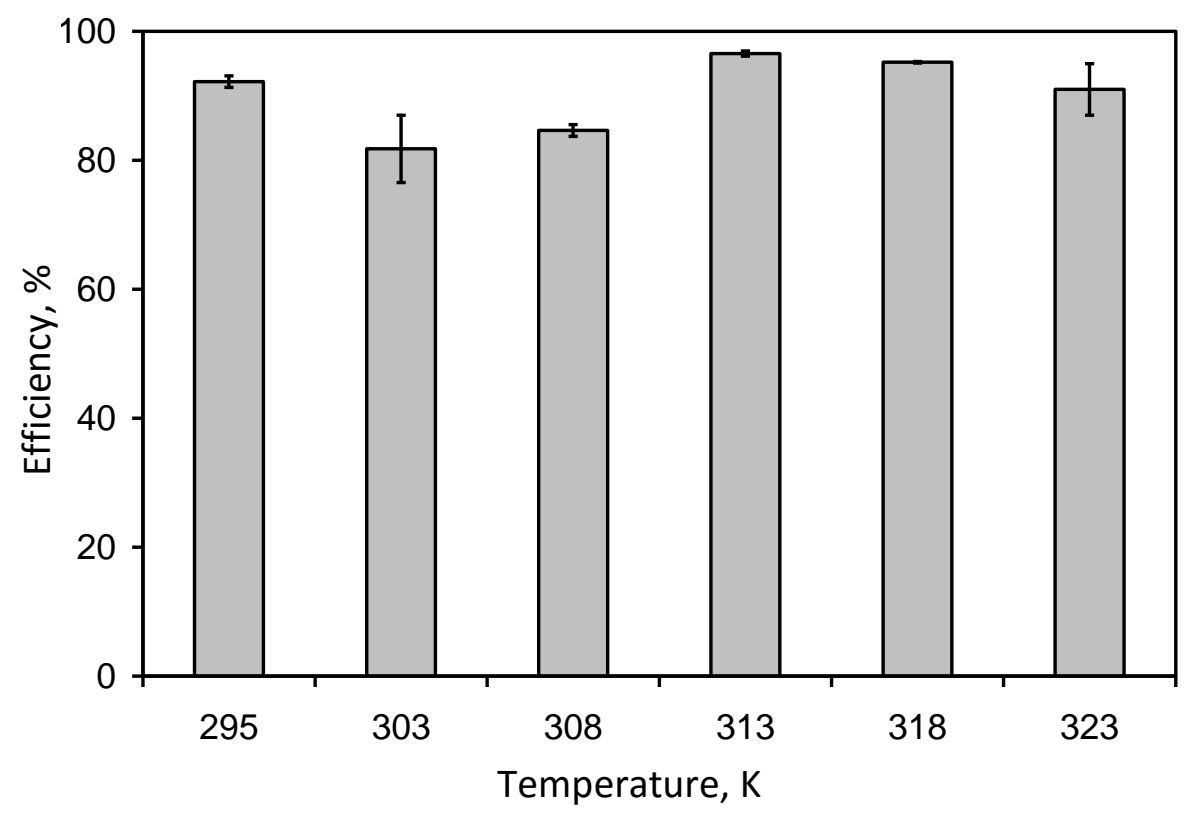

Figure 11. Dependence of corrosion inhibition efficiency on the solution temperature. The data were obtained from EIS measurements recorded on CS in the absence and presence of $3 \mathrm{mM}$ of AA in $0.5 \mathrm{M} \mathrm{HCl}$

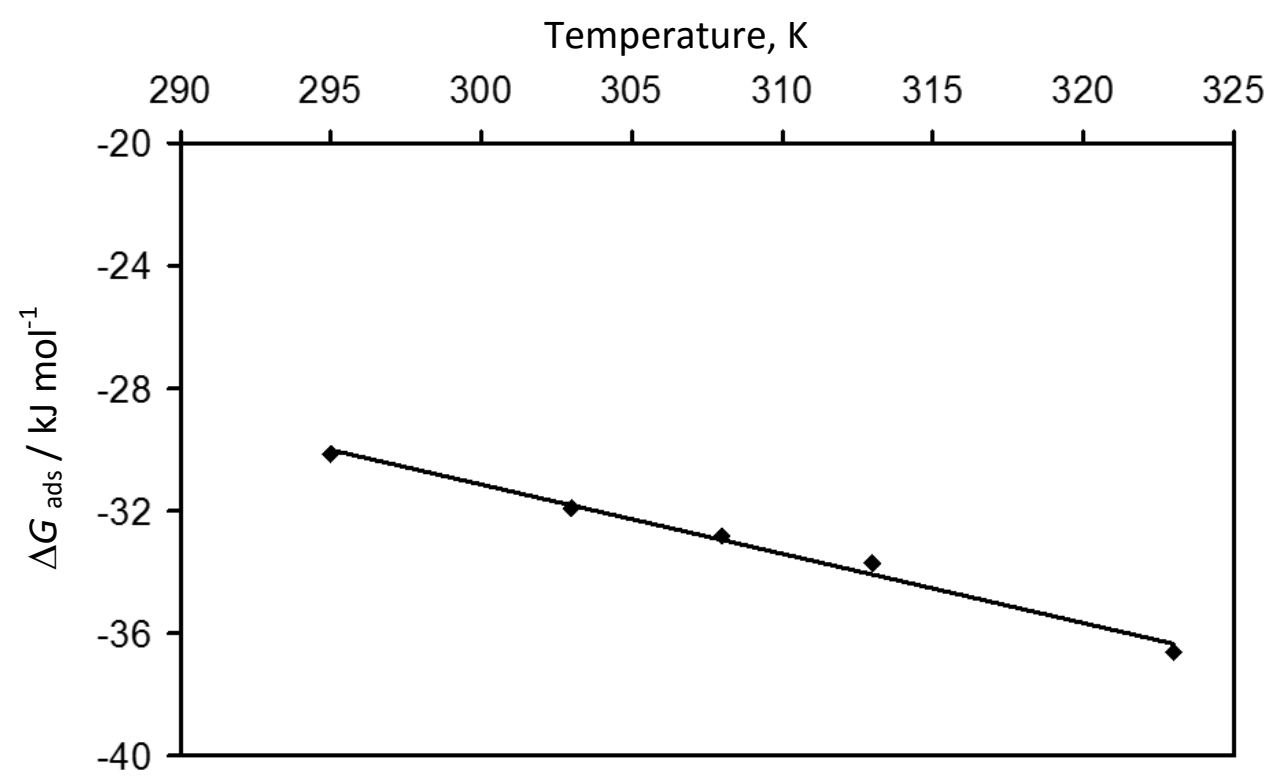

Figure 12. The dependence of apparent Gibbs free energy of adsorption on temperature. The data were obtained from EIS measurements recorded on CS at OCP and over a wide range of $A A$ concentration in the bulk electrolyte

\subsection{Effect of $\mathrm{pH}$}

The influence of $\mathrm{pH}$ on the $\mathrm{CS}$ corrosion inhibition efficiency by $\mathrm{AA}$ was also studied in $\mathrm{HCl}$, in a $\mathrm{pH}$ range from 0.35 to 3.5 , in the absence and presence of $3 \mathrm{mM}$ of $A A$, using EIS measurements. These measurements were performed at OCP, one hour after the stabilization of the CS electrode in the electrolyte at OCP. Corrosion inhibition efficiency values were then calculated from these measurements, and are presented in Fig. 13. The results show that AA offers high corrosion inhibition efficiency at all the investigated $\mathrm{pH}$ values. The corrosion inhibition efficiency of $A A$ remains stable over the investigated $\mathrm{pH}$ region, which could be linked to the good solubility of $A A$ in the electrolyte at all $\mathrm{pH}$ values. 


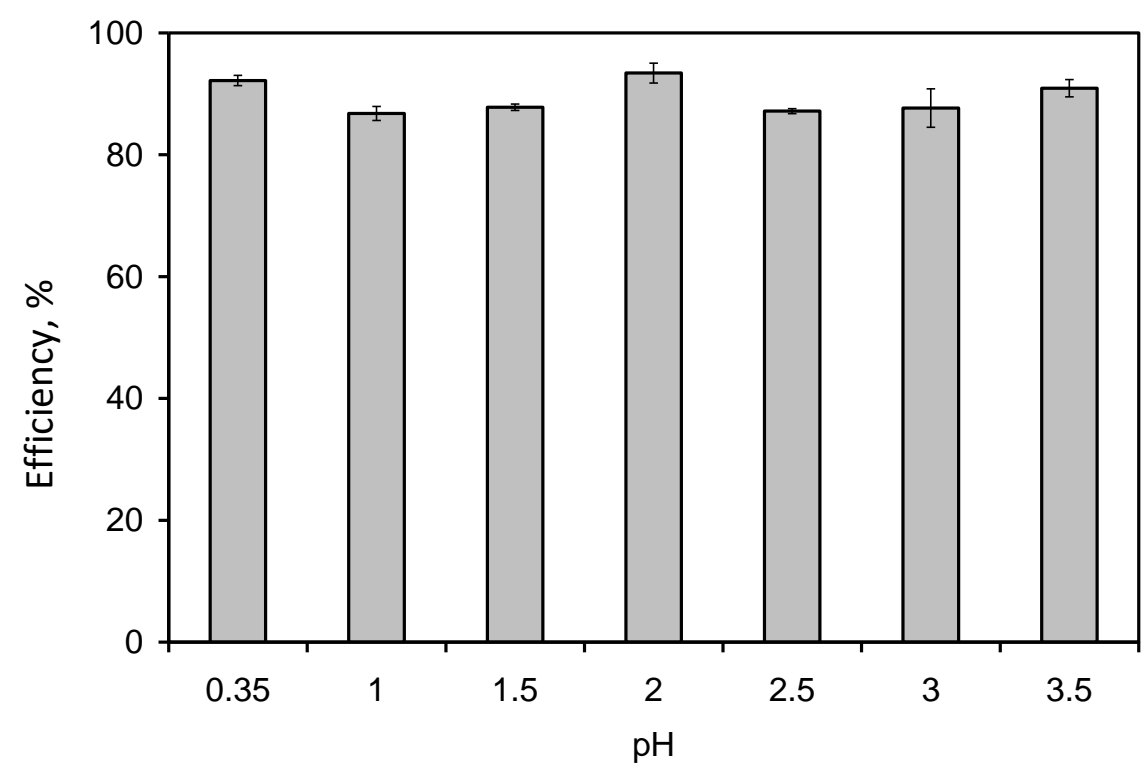

Figure 13. The inhibition efficiency of AA on CS general corrosion determined at various electrolyte $\mathrm{pH}$ values. The data were derived from EIS measurements recorded in the absence and presence of $3 \mathrm{mM}$ of $\mathrm{AA}$ in $\mathrm{HCl}$ electrolyte at $295 \mathrm{~K}$

\section{Conclusions}

- EIS, Tafel and weight-loss measurements were used to evaluate the corrosion inhibition efficiency of AA. The corrosion inhibition efficiency increases with increasing the AA concentration. A very good agreement between results obtained by the three techniques was demonstrated.

- Tafel measurements revealed that AA inhibits both partial corrosion reactions, and can thus be considered to be a mixed-type inhibitor.

- The adsorption of AA was described by the Langmuir adsorption isotherm. The corresponding thermodynamic values showed that the AA adsorption is a spontaneous process, driven by an entropy increase.

- Kinetic measurements showed that high inhibition efficiency (ca. 84\%) is achieved within 30 minutes of the immersion of the freshly polished CS surface in the presence of AA in the acid solution. Complete equilibrium is achieved after ca. $1 \mathrm{~h}$.

- Temperature-dependent measurements confirmed that AA maintains its high corrosion inhibition efficiency up to $323 \mathrm{~K}$, which indicates that the adsorbed AA monolayer is chemically stable in the investigated temperature range.

- The corrosion inhibition efficiency remains high with an increase in solution $\mathrm{pH}$.

- PM-IRRAS measurements confirmed the chemical identity of the adsorbed AA layer. The formed layer is of an amorphous structure and seems to be chemisorbed.

- The inhibitor shows a good protection of the CS of different surface roughness.

Acknowledgments: The authors express their sincere acknowledgment to the Natural Science and Engineering Research Council of Canada, to the Ministry of Higher Education and Al-Mergib University, Alkhums-Libya, and to the Summer Undergraduate Research program in the Faculty of Engineering at McGill University for providing the support for this research. 


\section{References}

[1] M. A. Quraishi, D. Jamal, Corrosion 56 (2000) 156.

[2] M. S. Morad, A. M. Kamal El-Dean, Corrosion Science 48 (2006) 3398.

[3] M. Lebrini, M. Traisnel, M. Lagrene, B. Mernari, F. Bentiss, Corrosion Science 50 (2007) 473.

[4] M. A. Migahed, I. F. Nassar, Electrochimica Acta 53 (2008) 2877.

[5] M. A. Migahed, M. Abd-El-Raouf, A. M. Al-Sabagh, H. M. Abd-El-Bary, Electrochimica Acta 50 (2005) 4683.

[6] M. A. Quraishi, D. Jamal, Materials Chemistry and Physics 71 (2001) 202.

[7] M. A. Quraishi, D. Jamal, Corrosion 56 (2000) 983.

[8] C. Kustu, K. C. Emregul, O. Atakol, Corrosion Science 49 (2007) 2800.

[9] A. Fouda, A. Attia, A. Negm, Journal of Metallurgy 2014 (2014)

[10] N. Ngobiri, E. Oguzie, Y. Li, L. Liu, N. Oforka, O. Akaranta, International Journal of Corrosion 2015 (2015)

[11] M. Salasi, T. Shahrabi, E. Roayaei, M. Aliofkhazraei, Materials Chemistry and Physics 104 (2007) 183.

[12] M. A. Amin, S. S. Abd El Rehim, H. T. M. Abdel-Fatah, Corrosion Science 51 (2009) 882.

[13] V. Hluchan, B.L. Wheeler, N. Hackerman, Werkstoffe und Korrosion 39 (1988) 512.

[14] Jun Liu, Investigation of inhibition effect of some amino acids against steel corrosion in chloride-containing alkaline solution, Master Thesis, Department of Materials Science and Engineering, Faculty of Mechanical, Maritime and Materials Engineering, 2014, Delft University of Technology.

[15] ASTM G 31-72 Standard Practice for Laboratory Immersion Corrosion Testing of Metals (reapproved 1995).1990.

[16] J.-B. Jorcin, M. E. Orazem, N. Pébère, B. Tribollet, Electrochimica Acta 51 (2006) 1473.

[17] S. Omanovic, S. G. Roscoe, Corrosion 56 (2000) 684.

[18] M. Yadav, S. Kumar, N. Kumari, I. Bahadur, E. E. Ebenso, International Journal of Electrochemical Science 10 (2015) 602.

[19] A. Chetouani, M. Daoudi, B. Hammouti, T. Ben Hadda, M. Benkaddour, Corrosion Science 48 (2006) 2987.

[20] M. Elayyachy, A. El Idrissi, B. Hammouti, Corrosion Science 48 (2006) 2470.

[21] S. Ghareba, S. Omanovic, Corrosion Science 52 (2010) 2104.

[22] A. Popova, M. Christov, A. Zwetanova, Corrosion Science 49 (2007) 2131.

[23] M. Lebrini, M. Lagrenee, H. Vezin, M. Traisnel, F. Bentiss, Corrosion Science 49 (2007) 2254.

[24] V. R.Saliyan, A. V. Adhikari, Corrosion Science 50 (2008) 55.

[25] M. Ozcan, Journal of Solid State Electochemistry 12 (2008) 1653.

[26] G. Shustak, A. J. Domb, D. Mandler, Langmuir 20 (2004) 7499.

[27] A. Mahapatro, D. M. Johnson, D. N. Patel, M. D. Feldman, A. A. Ayon, C. M. Agrawal, Langmuir 22 (2006) 901.

[28] S. Lin, C. Chen, Y. Chan, C. Lin, H. Chen, Journal of Physical Chemistry B 105 (2001) 4951.

[29] F. Bentiss, M. Lagrenée, M. Traisnel, Corrosion 56 (2000) 733.

[30] F. Bentiss, M. Traisnel, N. Chaibi, B. Mernari, H. Vezin, M. Lagrenee, Corrosion Science 44 (2002) 2271.

[31] M. M. Osman, M.N. Shalaby, Materials Chemistry and Physics 77 (2002) 261.

[32] C. H. Hamann, A. Hamnett, W. Vielstich in Electrochemistry, Wiley-VCH, Germany, 1998.

C 2015 by the authors; licensee IAPC, Zagreb, Croatia. This article is an open-access article distributed under the terms and conditions of the Creative Commons Attribution license (http://creativecommons.org/licenses/by/4.0/) (c) (E) 